\title{
The Business Cycle And Impacts Of Economic News On Financial Markets
}

\author{
Esin Cakan, University of New Haven, USA
}

\begin{abstract}
By jointly modeling returns and volatilities, we find that unemployment news has no significant impact on US stock market returns, but instead on stock market volatility. There is also a significantly positive relation between the long-term bond return and unemployment news during economic expansions, indicating that U.S. government bonds might be a hedge against unemployment news. Inflation news affects both stock and bond market returns negatively during expansions. Both unemployment and inflation news surprises also have more impact on volatility during economic recessions than during expansions.
\end{abstract}

Keywords: News Surprises; Stock Price Returns; Bond Market; GARCH; Volatility

\section{INTRODUCTION}

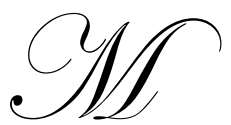

acroeconomic variables are candidates for systematic risk factors and macroeconomic news can exert impacts on firms' fundamentals, such as their future cash flows and risk-adjusted discount rates. As a result, macroeconomic news can affect asset returns. Along this line, the impact of macroeconomic news announcements on financial markets has received considerable attention in the literature. A partial list of these studies include Pearce and Roley (1985), Flannery and Protopapadakis (2002) and Adams et al. (2004) on stock markets; Jones et al. (1998), Balduzzi et al. (2001), Faust, Wang and Wright (2007) on bond markets; and Andersen, Bollerslev, Diebold and Vega (2007) on both stock and bond markets. The general conclusion from these studies is that macroeconomic news announcements affect returns and/or volatilities of returns. Some of these studies (e.g., Andersen et al., 2007) also document asymmetric impacts of good versus bad news on financial market returns and volatilities and generally report a larger impact of bad news than that of good news. However, it may not be appropriate to examine the effects of good or bad news in an unconditional manner, because the same news might have very different or even opposite effects on the financial markets during different economic states. The idea was first proposed by Blanchard (1981) who shows that, in the equilibrium, the same news might be good or bad for financial assets, depending on the state of the economy. Therefore, state of the economy can be the main reason that causes different impacts of the same news on the markets. Only a few subsequent studies (McQueen and Roley, 1993; Veronesi, 1999; Boyd et al., 2005) have further examined asymmetric impacts of the good and bad economic news on the stock markets during different business cycle stages. Most relevant to our study, Boyd et al. (2005) argue that stock price responds negatively to news of rising unemployment during contractions and positively during expansions.

In this study, we investigate how two economic news announcement surprises; namely, unemployment and inflation, affect the behavior of daily equity and Treasury bond market returns during the business cycles in the U.S from 1981 to 2005. As noted earlier, numerous earlier empirical studies do not focus on the conditional nature of good versus bad economic news during different macroeconomic conditions, with the notable exception of Boyd et al. (2005). ${ }^{1}$ The study further extends the existing literature (e.g., Boyd et al., 2005) in the following aspects. First, we analyze the impact of both unemployment rate and inflation announcements and model both returns and

\footnotetext{
${ }^{1}$ Recently, both Andersen (2007) and Yang et al. (2009) provide more evidence in line with Boyd et al. (2005) in their examination of the stock-bond relationship. Nevertheless, due to the data limitations, we can only focus on the differential impacts of macroeconomic news related to the business cycle without further allowance for good versus bad news at different stages of the business cycles.
}

(C) 2012 The Clute Institute http://www.cluteinstitute.com/ 
volatility simultaneously, while Boyd et al. (2005) exploit only the unemployment rate news on returns. More importantly, as theoretically argued in Engle (1982) and empirically illustrated in Grier and Perry (1993), failure to allow for conditional heteroskedasticity would result in the misspecification of residuals and thus potentially misleading inference on statistical significance of regression parameters. Second, we measure the unexpected component of the announcements (i.e., the surprise) using the survey data on market participants' expectations of these announcements, while Boyd et al. (2005) use regression models to obtain an unexpected part of the announcement as a surprise. Pearce and Roley (1985) show that the surveys are more accurate, in the sense of having lower mean squared errors, than the forecasts from standard autoregressive time series models.

\section{THEORETICAL BACKGROUND, METHODOLOGY AND DATA}

The data used in this paper cover the period January 2, 1981 to December 30, 2005. The data include stock prices, bond yields, actual values and survey-based expectations of announcements of unemployment rate and producer price index (PPI). The stock return data are daily stock returns on the S\&P 500 and the Russell 2000 price index, which represent large and small stocks, respectively. Daily stock returns are calculated as the log difference of the daily closing stock prices in the S\&P 500 stock Index and R2000 Index. The bond data are historical yields on the 10-year Treasury bonds with constant maturity from the Federal Reserve Board. The daily changes of yields are used to measure the 10-year government bond returns. There are 6239 daily observations for these returns.

The unemployment rate and the PPI are the two most important pieces of economic news. The unemployment rate releases have a long and accurately dated time series, which are generally made before the stock market opens, specifically at 9:00 AM before March 1982 and at 8:30 A.M after April 1982. There are 296 monthly unemployment announcements during the sample period. The PPI measures the change in the selling prices received by domestic producers for all finished goods. There are 297 monthly PPI announcement days.

The expectations data on macroeconomic announcements are the survey data from Money Market Service (MMS). The MMS data are most commonly used in the studies of economic announcements. Money Market Services (MMS) has conducted telephone surveys normally one week or less before any news release since late 1977. Pearce and Roley (1985) find MMS forecasts unbiased and efficient.

The business cycles data is taken from National Bureau of Economic Research (NBER). The data set covers the period January 2, 1981 to December 30, 2005 with 6,239 days. Expansion and contractions are based on NBER's dating of business cycle turning points. There are three recessionary periods in the same period, which include 666 contraction days and 5,573 expansion days.

To examine the effect of each announcement on the return of stock market mean and conditional volatility, we focus on the news surprise effect of announcements. Let $F_{i}$ denote the median of the MMS forecast survey and $\mathrm{A}_{\mathrm{i}}$ the released value of announcement $i$. We measure the surprise in announcements $i$ as:

$E_{t}=A_{t}-F_{t}\left(A_{t}\right)$

This surprise $E_{\mathrm{t}}$ can be divided by their standard deviation across all observations to facilitate interpretation. The standardized surprise measure is as follows:

$$
S_{i}=\frac{E_{i}}{\sigma_{i}}
$$

Since the $\sigma_{i}$ is constant across all observations for a given announcement $\mathrm{i}$, this adjustment does not affect either the significance of the estimates or fit of regression (Balduzzi et al., 2001). The standardized surprise allows us to compare the size of regression coefficients across different announcements. 
In the data set, there are 296 announcement days. Out of 296 days, US economy was in recession for 32 days and in expansion for 264 days when unemployment rate news was announced; and in recession for 30 and in expansion for 267 days when inflation news was announced.

Following Boyd et al. (2005), to investigate potentially asymmetric response of the stock price index to the unemployment and inflation news depending on the state of the economy, we estimate the following mean model for asset returns:

$R_{t}=\alpha_{0}+\alpha_{1}$ br.surprise $a_{t}^{a}+\alpha_{2}$ be.surprise $a_{t}^{a}+u_{t}$

where $R_{t}$ denotes the change in the logarithm of the stock price index from the market close of business day or percentage change of the bond price on day $t ; b r$ and $b e$ denote the business recession and expansion days as binary dummies, respectively; surprise denotes the standardized surprise size of the considered news announcement, which is the standardized unanticipated component of each announcement; and a denotes the announcement news as the unemployment rate or the PPI news.

Extending Boyd et al. (2005), in addition to mean equation, we also model the conditional variance to capture the effect of volatility on the mean equation, as given in Equation (4). We modify the EGARCH $(1,1)$ model of Nelson (1991) by allowing for surprise size effects during business cycles as follows:

$$
\log \sigma_{t}^{2}=\beta_{0}+\beta_{1}\left|\frac{u_{t-1}}{\sigma_{t-1}}\right|+\beta_{2} \frac{u_{t-1}}{\sigma_{t-1}}+\beta_{3} \log \sigma_{t-1}^{2}+\beta_{4} . \text { br.surprise } e_{t}^{a}+\beta_{5} . \text { be.surprise } e_{t}^{a}+v_{t}
$$

where $v_{t}$ is a white noise and $\beta_{0}, \beta_{1}, \beta_{2}, \beta_{3}, \beta_{4}$, and $\beta_{5}$ are constant parameters. We expect a negative sign for $\beta_{2}$ for an asymmetric shock. Otherwise, we use standard GARCH with surprise size considering business cycles given as:

$$
\sigma_{t}^{2}=\beta_{0}+\beta_{1} \sigma_{t-1}^{2}+\beta_{2} u_{t-1}^{2}+\beta_{3} \text { br.surprise } e_{t}^{a}+\beta_{4} \text { be.surprise } a_{t}^{a}+v_{t}
$$

We use equation (5) for modeling bond market which is explained in detailed in the next section. We estimate the model by the quasi-maximum likelihood (QML) method. It is well known that QML parameter estimates can be consistent, even though the conditional log-likelihood function assumes normality while asset returns are known to be skewed and leptokurtic.

\section{EMPIRICAL RESULTS}

\section{Response of Stock Returns for Macroeconomic News}

In Table 1, Panel A shows the results for S\&P 500 and Russell 2000 price index returns and summarizes the results of estimation for equations (3) and (5) simultaneously. The coefficients $\alpha_{1}$ and $\alpha_{2}$ are not statistically significant, which leads us to conclude that stock returns do not rise/fall with a labor market announcement surprise during different economic states. This result is contrary to Boyd et al. (2005) findings that an increase in unemployment is good news for the stock market during economic expansions and bad news during economic recessions. We do not find supportive empirical results for that hypothesis. It might be because of the length and type of the data they use. They follow a definition of Stock and Watson for business cycles instead of NBER announcements. Besides, they calculate the surprise size as a residual (shock) vector from an estimated regression, while we use the survey data. ${ }^{2}$ However, the results of conditional variance equations show both markets have different reactions to the unemployment news surprises. We find some evidence for asymmetric volatility and macroeconomic news that affect the financial markets. First, the conditional volatility EGARCH model is

\footnotetext{
${ }^{2}$ Boyd et al. (2005) use the data from June 1972 to December 2000. They did not use forecasts made by Money Market Services International (MMS) to identify the surprise element of the unemployment rate announcement since MMS forecasts have only been available since November 1977, whereas their data goes back to January 1962. They use their own time-series models to forecast the unemployment rate announcement and its unanticipated component.
} 
appropriate for the stock market returns. For both indices, asymmetric volatility coefficients of the models, $\beta_{2}$, are negative and statistically significant. Focusing on the dummies in conditional covariance coefficients, the coefficients $\beta_{3}$ and $\beta_{4}$ are statistically significant. In addition, all estimated coefficients, which are statistically significant, show positive values, indicating that they raise the conditional variance. This implies important information - that the release of this news may increase future uncertainty and, therefore, investors need more compensation for the increased risk. In other words, inferred from the empirically established link between trading volume and volatility, the positive coefficients refers that the increased volatility in response to macroeconomic news announcements arises from the increased volume of trade following the announcement. The results show that the impact of surprise size of unemployment news on the conditional volatility differs across states of the economy.

Analyzing the results in more detail, in recession, the size of the impact of unemployment news in conditional volatilities is significant for S\&P 500 and R2000. In Table 1, $\beta_{4}$ 's are statistically significant and greater than $\beta_{5}$ indicating that unemployment news has more impact on stock returns volatility in recession more than in expansion and creates an asymmetric impact on volatility between business cycles ( 0.1775 and 0.0369 for S\&P 500, 0.1437 and 0.025 for R2000 in recession and expansion, respectively). In summary, both stock indices become more risky under the possibility of bad economic news from the labor market.

In Table 1, Panel B summarizes the results of PPI news surprises on equity markets. Equity market returns result negatively with a bad inflation surprise during expansions. In our models, $\alpha_{1}$ measures the stock price sensitivity to PPI news during contractions and $\alpha_{2}$ measures the sensitivity of stock returns during expansions. Notice that since $\alpha_{1}$ is not statistically significant, PPI news does not have a significant effect on stock prices in contractions. In expansions, $\alpha_{2}$ is negative and statistically significant for both indices, and PPI announcement shock has a negative and significant effect on stock prices. Moreover, the good news in PPI announcement shocks in good times increase the mean returns of both S\&P 500 and Russell 2000 price indices and bad news decreases the mean returns of both indices. One explanation is that, in good times, the bad economic news about inflation raises the expectations for the future interest rates to increase. An increase in the nominal interest rates might reduce the returns in the stock market. There are different channels by which inflation surprises may affect stock prices. Many studies found that higher expected inflation rate depresses stock prices. Therefore, any positive inflation surprise (bad economic news) that raises the agents' expectations for future inflation will affect the stock market in a negative way. One explanation for this phenomenon is that investors discount corporate earnings by using nominal interest rates. Firms sell securities ahead of expected higher interest rates in the future, pushing up the interest rates upward, assuming the stock and bonds are substitutes.

\section{Response of Bond Returns To Macroeconomic News}

The empirical results of this study, given in Panel B in Table 2, support that bond price also decreases as a response to a given positive inflation surprise. The bond price decreases in expansion leading to an increase in nominal interest rates. This result is consistent with the above explanation by which stock prices come down due to an increase in interest rates and price of the bonds go down, resulting in an increase in nominal interest rates. The second possible channel occurs because policy makers typically react to inflation news. As the inflation is higher than expected, the general belief is that policy makers will use contradictory monetary policies which impact negatively on firms' cash flows and lower stock prices. Similarly, with a positive inflation surprise, agents revise their expectations higher on current money demand, leading to higher interest rates. As a result, it lowers the stock prices, assuming the Fed will maintain its previous monetary growth objectives.

Panel A in Table 2 reports the result of mean and conditional volatility estimations for the 10 -year bond price changes. In the mean equation, both coefficients $\alpha_{1}$ and $\alpha_{2}$ are positive but only $\alpha_{2}$ is statistically significant for the 10 year bond, which suggests an increase in bond prices in response to a positive unemployment rate surprise during economic expansion. As the unemployment increases, the future expected interest rates come down while the bond price increases. Therefore, the return on bonds increases. The results are consistent with Boyd et al. (2005) paper for the 10-year bond. Long term bond returns become risky during expansions. One explanation for that result is that long term U.S government bonds are more secure and they are complete hedge against unexpected unemployment. To summarize, the results on government bond price responses to the arrival of unemployment new is different from that of the stock market response. 
Table 1: Mean and Variance of Stock Returns in Response to Macroeconomic News

This table summarizes the mean and conditional volatility of stock returns with EGARCH model. br and be denotes for business recessions and expansions as a binary variable, respectively. surprise ${ }^{a}$ is the standardized surprise component of the corresponding news announcement.

$$
\begin{aligned}
& R_{t}=\alpha_{0}+\alpha_{1} . \text { br.surprise } e_{t}^{a}+\alpha_{2} . \text { be.surprise } a_{t}^{a}+u_{t} \\
& \log \sigma_{t}^{2}=\beta_{0}+\beta_{1}\left|\frac{u_{t-1}}{\sigma_{t-1}}\right|+\beta_{2} \frac{u_{t-1}}{\sigma_{t-1}}+\beta_{3} \log \sigma_{t-1}^{2}+\beta_{4} . \text { br.surprise } e_{t}^{a}+\beta_{5} . \text { be.surprise } e_{t}^{a}+v_{t}
\end{aligned}
$$

\begin{tabular}{|c|c|c|}
\hline & Panel A & Panel B \\
\hline & UR News Announcements & PPI News Announcements \\
\hline \multicolumn{3}{|c|}{ Mean Equation Coefficients } \\
\hline$\alpha_{0}$ & $-0.0285^{* * *}$ & $0.0267^{* * *}$ \\
\hline$\alpha_{1}$ & 0.0826 & 0.0821 \\
\hline$\alpha_{2}$ & 0.0584 & $-0.1939^{* * *}$ \\
\hline \multicolumn{3}{|c|}{ Variance Equation Coefficients } \\
\hline$\beta_{0}$ & $-0.074^{* * * *}$ & $-0.085^{* * * *}$ \\
\hline$\beta_{1}$ & $0.0953^{* * *}$ & $0.109^{* * *}$ \\
\hline$\beta_{2}$ & $-0.059^{* * * *}$ & $-0.060^{* * * *}$ \\
\hline$\beta_{3}$ & $0.9874^{* * *}$ & $0.9855^{* * *}$ \\
\hline$\beta_{4}$ & $0.1775^{* * *}$ & -0.1444 \\
\hline$\beta_{5}$ & $0.0369^{* *}$ & $0.0705^{* * *}$ \\
\hline
\end{tabular}

Table 2: Mean and Variance of Bond Returns in Response to Macroeconomic News

This table summarizes the mean and conditional volatility of bond returns with GARCH model where $b r$ and $b e$ denote for business recessions and expansions as a binary variable, respectively, and surprise ${ }^{a}$ is the standardized surprise component of the corresponding news announcement.

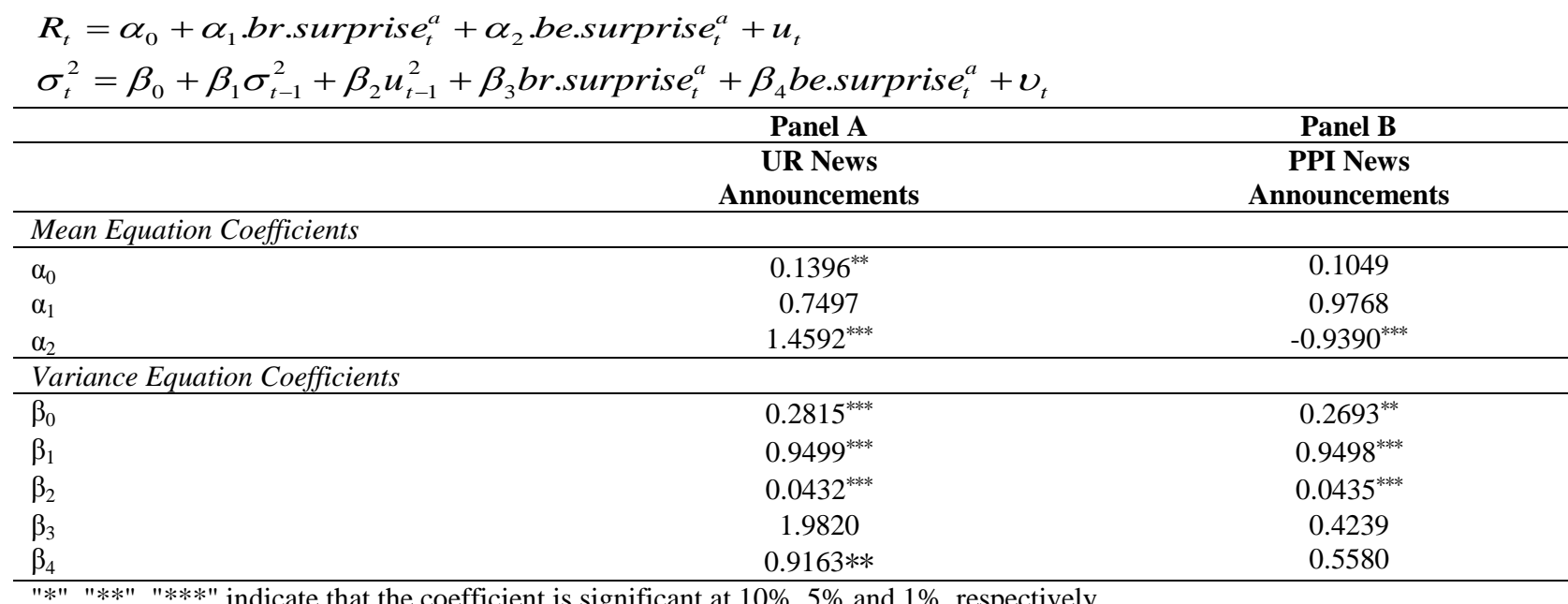

Panel B of Table 2 summarizes the response of 10-year bond returns to the PPI news announcement surprises. As may be well expected, the mean equation coefficients, $\alpha_{1}$ and $\alpha_{2}$, are negative and statistically significant during recessions, implying that bad economic news about the inflation decreases the bond prices. 


\section{CONCLUSION}

This study investigates the interaction between announcement shocks and the mean and volatility in the stock and bond markets during the business cycles. Our results show that, on average, stock returns neither rise nor fall when there is a labor market announcement during different economic states, which is a contradiction to the results of Boyd et al (2005). However, the conditional volatility of stock market returns increases with unemployment news surprises during business cycles, which increase more during recessions than during expansions. By contrast, long-term bond return rises when there is unemployment news in expansions, but it does not respond significantly in recession periods. Therefore, U.S. government bonds might be a hedge against unemployment news.

Finally, inflation shocks affect both markets in different ways from the unemployment shocks. The news in inflation-related announcement shocks in expansion decreases the mean returns of S\&P 500, while equity markets become less risky in good times. Bond returns decrease with bad economic news about the inflation during recessions.

\section{AUTHOR INFORMATION}

Dr. Esin Cakan is an Assistant Professor at Department of Economics, University of New Haven. She got her Ph. D. in Financial Economics from The Graduate School and University Center of City University of New York. Her main research interests are exchange rate markets, macroeconomics, financial markets with a specific interest in financial econometrics. E-mail: ecakan@ newhaven.edu

\section{REFERENCES}

1. Adams, G., McQueen G., Wood R., 2004. The Effects of Inflation News on High Frequency Stock Returns, Journal of Business, 77, 547-574.

2. Andersen, T., T. Bollerslev, F.X. Diebold and C. Vega, 2007. Real-time price discovery in stock, bond and foreign exchange markets, Journal of International Economics 73, 251-277.

3. Balduzzi, P., Elton, E.J., Green, T.C., 2001. Economic news and bond prices: Evidence from the US Treasury market, Journal of Financial and Quantitative Analysis, 36, 523-543.

4. Blanchard, O. J., 1981. Output, the stock market, and interest rates, American Economic Review, 71, 132143.

5. Boyd, J., Hu, J., Jagannathan, R., 2005. The stock market's reaction to unemployment news: Why bad news is usually good for stocks, Journal of Finance, 60, 649-672.

6. Engle, R. F., 1982. Autoregressive Conditional Heteroscedasticity with Estimates of the Variance of U.K. Inflation. Econometrica, 50, 987-1008.

7. Flannery, M.J., Protopapadakis, A., 2002. Macroeconomic factors do influence aggregate stock returns, Review of Financial Studies, 15, 751-782.

8. Grier, K.B., Perry, M., 1993. The Effect of Money Shocks on Interest Rates in the Presence of Conditional Heteroskedasticity, Journal of Finance, September 1993 p. 1445-55.

9. McQueen, G., Roley, V., 1993. Stock prices, news and business conditions. Review of Financial Studies, 6, 683-707.

10. Jones, C.M., Lamont, O., Lumsdain, R., 1998. Macroeconomic news market volatility, Journal of Financial Economics, 47, 315-337.

11. Nelson, D., 1991. Conditional heteroskedasticity in asset returns: A new approach, Econometrics, 59, $347-$ 70.

12. Pearce, D.K., Roley, V., 1985. Stock prices and economics news, Journal of Business, 58, 49-67.

13. Veronesi, P., 1999. Stock market overreaction to bad news in good times: A rational expectations equilibrium model, Review of Financial Studies, 12, 975--1007.

14. Yang, J., Zhou, Y., Wang, Z., 2009. The Stock-Bond Correlation and Macroeconomic Conditions: One and A Half Centuries of Evidence. Journal of Banking and Finance, 33, 670 - 680. 